\title{
How effective is intra-cuff lignocaine in reducing post-operative sore throat and emergence cough: a comparative study
}

\author{
Jithin Mathew Abraham ${ }^{1 *}$, Saramma Abraham², Sangeetha Merrin Varghese $^{3}$
}

\author{
${ }^{1}$ Department of Anaesthesiology, Believers Church Medical College, Thiruvalla, Kerala, India \\ ${ }^{2}$ Department of Anaesthesiology, Pushpagiri Medical College, Thiruvalla, Kerala, India \\ ${ }^{3}$ Department of Community Medicine, Believers Church Medical College, Thiruvalla, Kerala, India
}

Received: 05 May 2020

Revised: 06 June 2020

Accepted: 08 June 2020

\section{*Correspondence:}

Dr. Jithin Mathew Abraham,

Email: sangjithin2011@gmail.com

Copyright: (C) the author(s), publisher and licensee Medip Academy. This is an open-access article distributed under the terms of the Creative Commons Attribution Non-Commercial License, which permits unrestricted non-commercial use, distribution, and reproduction in any medium, provided the original work is properly cited.

\begin{abstract}
Background: Sore throat and cough during emergence are common side effects of general anaesthesia and its incidence is reported by $30-70 \%$ of patients after tracheal intubation. Also, not to forget the hemodynamic fluctuations associated with it, adds on to the magnitude of the problem. Thinking of a simple and cost-effective way to tackle this problem, this study was undertaken to determine the benefits of using intra-cuff lignocaine to prevent post intubation sore throat and emergence cough. The objective of this study to assess the efficacy of intra-cuff $2 \%$ lignocaine solution, in reducing emergence cough and post-operative sore throat after extubation in general surgery patients intubated for 2-4 hours.

Methods: A prospective observational study where 100 ASA I and II status patients divided into 2 groups of 50 each was compared. In one group ETT cuff was filled with air, while in the other group, $2 \%$ plain lignocaine solution was used. Side effects like sore throat, coughing and blood pressure changes were assessed. Chi square and t-tests were used to compare the findings.

Results: Among those patients where intra-cuff lignocaine was used, only $27.5 \%$ complained of sore throat and $12.5 \%$ had emergence cough, whereas among those patients where intra-cuff air was used, $72.5 \%$ had post-operative sore throat and $87.5 \%$ of patients had cough on emergence.

Conclusions: This study proves that $2 \%$ intra-cuff lignocaine is an effective method in reducing post-operative sore throat and emergence cough and thereby beneficial in controlling the hemodynamic changes associated with emergence.
\end{abstract}

Keywords: Intra-cuff, Lignocaine, Sore throat, Intubation, Emergence cough

\section{INTRODUCTION}

Endotracheal anaesthesia is today the most common form of general anaesthesia and represents more than $80 \%$ of the means by which airway and ventilation is maintained for major surgeries. After intubation, inflating a cuff around the endotracheal tube maintains a seal, but at the same time, stimulates the irritant receptors in the trachea resulting in coughing during emergence from anaesthesia. Coughing induced by an endotracheal tube can complicate emergence from general anaesthesia especially in neurosurgical, ophthalmic, and vascular procedures. The incidence of coughing on emergence from general anesthesia in the presence of an endotracheal tube has been estimated between $38 \%$ and $96 \%{ }^{1}$ The patient when unable to tolerate an endotracheal tube coughs on the tube and this is also called bucking. 
Mucosal erosion may also be caused by mucosal dehydration and the patient bucking or coughing causing friction between the tracheal mucosa and the endotracheal tube, leading to post-operative sore throat. The overall incidence of sore throat after general anaesthesia is between $59-76 \%$ in $2002 .^{2}$

Manoeuvres to reduce coughing include the administration of IV or topically applied local anesthetics, IV narcotic administration and tracheal extubation in a deep plane of anesthesia; however, in many cases they are undesirable. ${ }^{3-7}$ The benefit of topically applied drugs before tracheal intubation is limited to a short time post application, as they are absorbed through the tracheo-bronchial mucosa. ${ }^{8}$

The cuff of an endotracheal tube is permeable to local anesthetics, including lignocaine by the process of simple diffusion. The cuff could act as a potential reservoir for a local anesthetic, allowing diffusion and subsequent anesthesia of the underlying mucosa. In this technique, plasma levels of lignocaine rise much slowly than in cases of direct topical application, thus reducing the risk of toxicity. Topical anesthetics applied in this manner might represent a novel technique to reduce adverse emergence coughing and post-operative sore throat. This study was undertaken to investigate the potential benefits of inflating the cuff of an endotracheal tube with lignocaine, rather than air i.e., to assess the efficacy of intracuff $2 \%$ lignocaine in reducing emergence cough and postoperative sore throat immediately and 4 hours after extubation in general surgery patients intubated for 2-4 hours and to study the efficacy of intra-cuff $2 \%$ lignocaine in maintaining normal blood pressure during emergence from general anesthesia.

\section{METHODS}

The study was done in Government Medical College, Kottayam, after obtaining approval from the Institutional Ethics Committee. It was a prospective observational study done in 2014 among 100 patients of ASA 1 and 2 status, belonging to age group of 18-60 years who underwent general anesthesia requiring intubation for a duration of 2 to 4 hours.

The practice of filling the cuff of the endotracheal tube with lignocaine as well as air is a routine practice in the institution. So, 50 patients who were given $2 \%$ intracuff lignocaine (study group) was observed and compared to 50 patients who were given intracuff air (control group). All patients satisfying the inclusion criteria were chosen alternatively to be in the study group and control group.

\section{Inclusion criteria}

Inclusion criteria were patients between 18 and 60 years of age with normal BMI and belonging to ASA PS-I and II.

\section{Exclusion criteria}

Exclusion criteria were allergy to lignocaine, patients with cardiovascular diseases, respiratory diseases, obesity, difficulty in intubation and risk of aspiration, Smokers, those undergoing airway, head and neck surgeries and those with a previous history of airway surgery.

\section{Sample size}

According to a previous study by Sagheer et al, minimum sample size required was 25 , based on the formula. ${ }^{9}$

$$
\begin{aligned}
& \mathrm{N}=[\mathrm{Z} 1-\alpha / 2 \sqrt{2} P(1-P)+\mathrm{Z} 1-\mathrm{B} \sqrt{P} 1(1-\mathrm{P} 1)+\mathrm{P} 2(1- \\
& \mathrm{P} 2)]^{2} \div(\mathrm{P} 1-\mathrm{P} 2)^{2}
\end{aligned}
$$

\section{Study procedure}

Data was collected with the help of a structured interview schedule after obtaining written informed consent. Age, weight, pulse rate and blood pressure were also recorded. Patients were advised to remain nil orally after midnight and all of them received tablet alprazolam $0.25 \mathrm{mg}$ and tablet ranitidine $150 \mathrm{mg}$ orally, the night before surgery and the morning of surgery. Pre-operative blood pressure was recorded in operation theatre after connecting the patient to continuous electrocardiogram, sphygmomanometer and pulse oxymetry. Intravenous cannulation with $18 \mathrm{G}$ catheter was established. Injection fentanyl 2 $\mathrm{mcg} / \mathrm{kg} / \mathrm{iv}$ injection midazolam $0.02 \mathrm{mg} / \mathrm{kg} / \mathrm{iv}$ and injection glycopyrolate $10 \mathrm{mcg} / \mathrm{kg} / \mathrm{iv}$ were administered as pre-medication. After 3 minutes of pre-oxygenation, anaesthesia was induced with $2 \mathrm{mg} / \mathrm{kg}$ propofol and tracheal intubation done after giving vecuronium 0.08 $\mathrm{mg} / \mathrm{kg}$ with appropriately sized cuffed endotracheal tube.

In the study group, endotracheal tube cuff was inflated with $2 \%$ lignocaine. In the control group, endotracheal tube cuff was inflated with air. The minimum volume needed to prevent leak around the tube as confirmed by palpation and auscultation was used in both cases. Anaesthesia was maintained with nitrous oxide: oxygen in the ratio 4:2. Muscle relaxation was attained by a maintenance dose $1 / 5^{\text {th }}$ of loading dose.

Ventilation was controlled. Muscle paralysis was reversed at the end of surgery with $0.05 \mathrm{mg} / \mathrm{kg}$ neostigmine and $10 \mathrm{mcg} / \mathrm{kg}$ glycopyrolate. Blood pressure was noted after reversal prior to extubation. The incidence of coughing, bucking before extubation were noted. Patient was extubated after fully deflating the cuff. Post-operatively sore throat was assessed immediately after surgery and after 4 hours.

\section{Statistical analysis}

SPSS v.16 was used to do the analysis. Association between categorical variables was assessed using Chisquare test and comparison of means was done using 
independent sample t-test. A p value less than 0.05 was considered to be statistically significant.

\section{RESULTS}

Majority of the patients $48.9 \%$ in the study group and $52.6 \%$ in the control group belonged to the age group between 31-50 years (Table 1). The study group and the control group were comparable with respect to age, gender, ASA grade, body weight, duration of surgery and baseline blood pressure (Table 2).

The number of coughing/bucking episodes following reversal showed a significant decrease among those patients who had received lignocaine in the ETT. Of all the patients who did not have any cough, $87.5 \%$ had received lignocaine. Of all the patients who had more than 4 episodes of coughs, all belonged to the group which received air (Figure 1).

The incidence of sore throat in the immediate postoperative period was also significantly lower in patients who had received lignocaine in ETT. Similar were the results of those who had experienced sore throat after 4 hours (Figure 2).
The mean rise of systolic BP following reversal was also significantly lower in the patients who received lignocaine $10.04 \mathrm{mmHg}$ when compared to air in the ETT $23.45 \mathrm{mmHg}$ (Table 3).

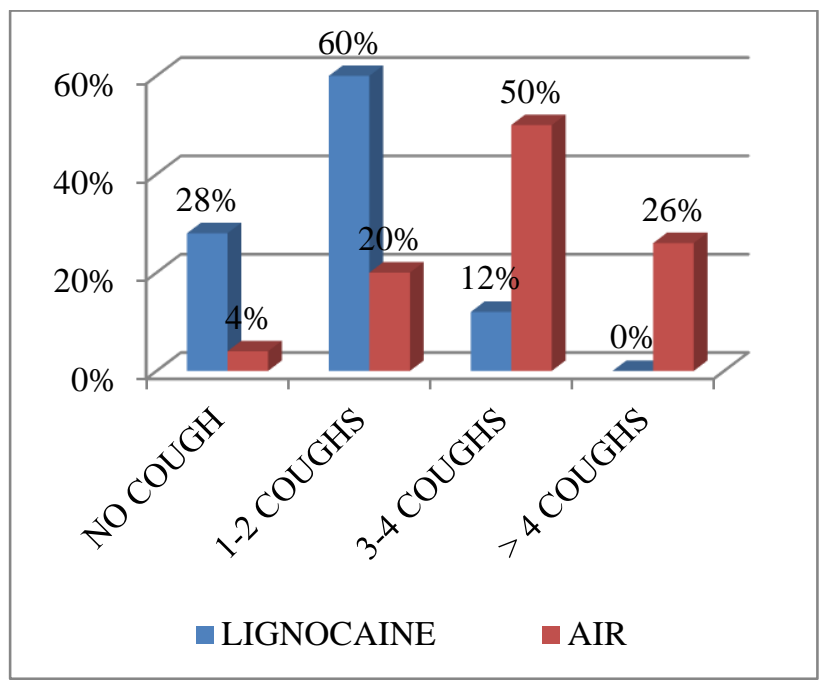

Chi square $=43.645, \mathrm{p}=0.001$.

Figure 1: Comparison of the number of emergence coughs in the two groups.

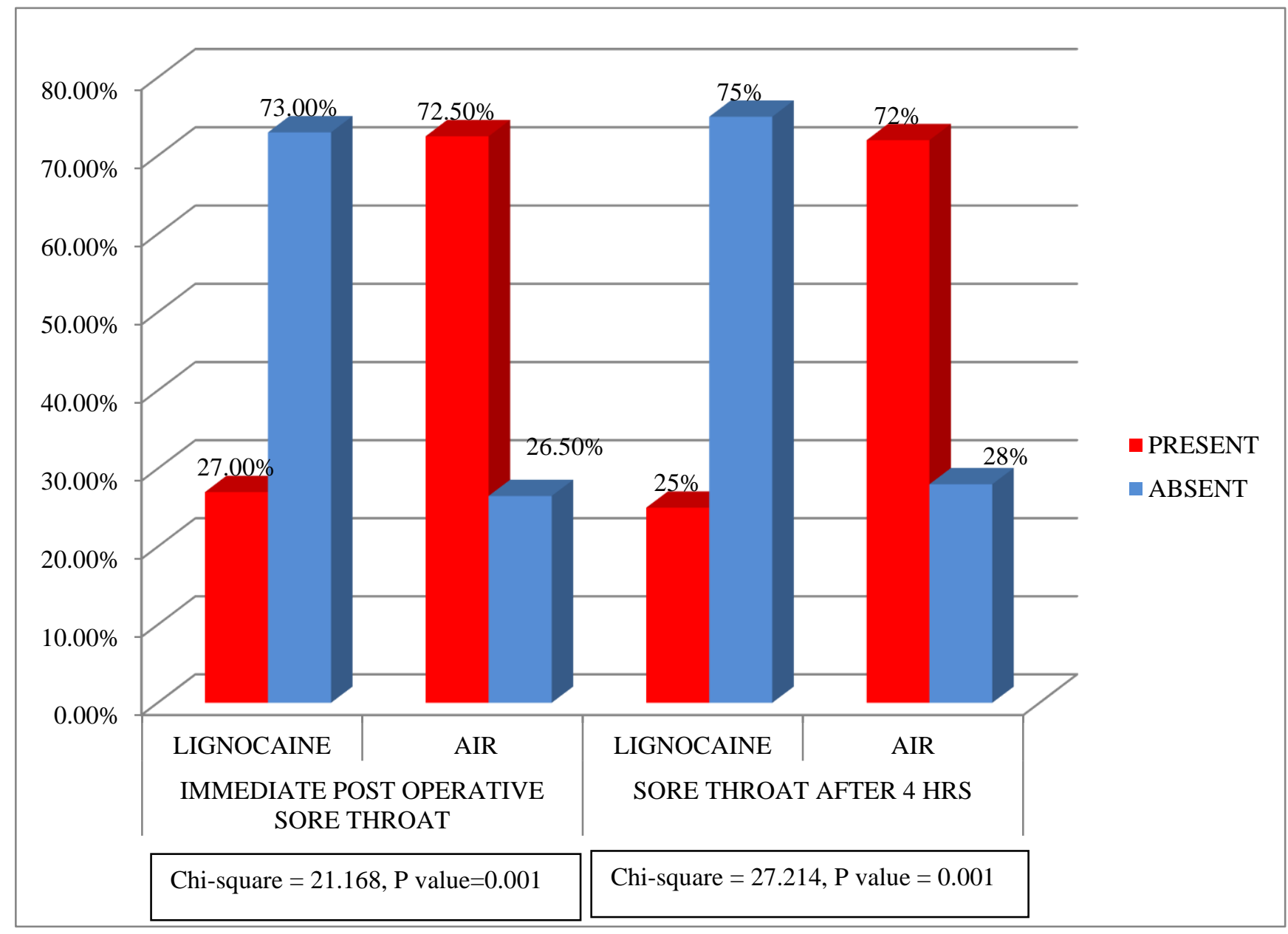

Figure 2: Comparison of immediate post-operative sore throat and sore throat after 4 hours. 
Table 1: Clinical profile of the study participants.

\begin{tabular}{|c|c|c|c|c|}
\hline \multirow{2}{*}{ Parameters } & Intervention group $(\mathrm{n}=\mathbf{5 0})$ & Control group (n=50) & \multirow[b]{2}{*}{ Chi square } & \multirow{2}{*}{ P value } \\
\hline & $\mathbf{N}(\%)$ & $\mathbf{N}(\%)$ & & \\
\hline \multicolumn{5}{|l|}{ Age in years } \\
\hline$\leq 30$ & $9(47.4)$ & $10(52.6)$ & \multirow[b]{3}{*}{1.92} & \multirow[b]{3}{*}{0.909} \\
\hline $31-50$ & $23(48.9)$ & $24(51.1)$ & & \\
\hline$>51$ & $18(52.9)$ & $16(47.1)$ & & \\
\hline \multicolumn{5}{|l|}{ Gender } \\
\hline Male & $33(52.4)$ & $30(47.6)$ & \multirow[b]{2}{*}{0.386} & \multirow[b]{2}{*}{0.534} \\
\hline Female & $17(45.9)$ & $20(54.1)$ & & \\
\hline \multicolumn{5}{|l|}{ ASA grade } \\
\hline ASA 1 & $37(50.7)$ & $36(49.3)$ & \multirow[b]{2}{*}{0.051} & \multirow[b]{2}{*}{0.822} \\
\hline ASA 2 & $13(48.1)$ & $14(51.9)$ & & \\
\hline \multicolumn{5}{|c|}{ Body weight in kg } \\
\hline$\leq 60$ & $22(42.3)$ & $30(57.7)$ & \multirow{3}{*}{3.410} & \multirow[b]{3}{*}{0.182} \\
\hline $61-70$ & $19(54.3)$ & $16(45.7)$ & & \\
\hline$>70$ & $9(69.2)$ & $4(30.8)$ & & \\
\hline
\end{tabular}

Table 2: Comparison of the mean duration of surgery and baseline BP in the two groups.

\begin{tabular}{|c|c|c|c|c|}
\hline Group & Mean & SD & T value & P value \\
\hline \multicolumn{5}{|c|}{ Duration of surgery } \\
\hline Lignocaine & 3.071 & 0.522 & \multirow[b]{2}{*}{0.743} & \multirow[b]{2}{*}{0.459} \\
\hline Air & 3.148 & 0.513 & & \\
\hline \multicolumn{5}{|c|}{ Baseline blood pressure } \\
\hline Lignocaine & 125.88 & 12.232 & \multirow[b]{2}{*}{1.048} & \multirow[b]{2}{*}{0.297} \\
\hline Air & 123.28 & 12.563 & & \\
\hline
\end{tabular}

Table 3: Change in systolic BP from baseline following reversal and in post-intubation period.

\begin{tabular}{|llllll|}
\hline Factor & Group & Mean & SD & T value & P value \\
\hline \multirow{2}{*}{ BP change at reversal } & Lignocaine & 10.039 & 4.071 & \multirow{2}{*}{9.591} & 0.001 \\
\cline { 2 - 4 } \multirow{2}{*}{ BP change at extubation } & Air & 23.452 & 9.012 & \\
& Lignocaine & 7.184 & 4.433 & \multirow{2}{*}{3.102} & \multirow{2}{*}{0.003} \\
\cline { 2 - 5 } & Air & 10.573 & 6.325 & \\
\hline
\end{tabular}

\section{DISCUSSION}

A general anesthetics technique that would allow patients to have a smooth extubation and a comfortable postoperative period is highly beneficial. This study was designed to compare the incidence of emergence cough and post intubation sore throat when intra cuff lignocaine was used compared to intra cuff air.

As per the results of the present study, all the patients were identical with respect to the age, weight, ASA grading and duration of surgery. Duration of surgery is a factor that affects the outcome and its comparability adds to the validity of the study.

Bucking or coughing on the endotracheal tube is one of the important adverse effects during emergence from general anaesthesia. Irritant or stretch stimuli in the trachea caused by the tube and its cuff are the presumed mechanisms which initiate the cough reflex through excitation of the sensory $\mathrm{C}$ fibres. This in turn produces secondary neuroplasticity which is involved in the development of post-operative coughing and sore throat. These nociceptive stimuli can be blocked by topically applied anesthetics. ${ }^{10}$ Sconzo et al demonstrated that lignocaine placed in the cuff of an endotracheal tube, diffused across the cuff membrane and Hirota et al concluded that lignocaine diffusion across tracheostomy cuff reduced tube discomfort. ${ }^{11,12}$

Combes et al conducted a study on intra cuff pressure and tracheal morbidity and showed that cuff pressure increased gradually during anesthesia in air inflated ETT cuff but remained stable in saline inlated ETT cuff. Fibreoptic examination revealed tracheal lesions at the time of extubation in all patients of the air group while only few had it in saline group. ${ }^{13}$ This also shows that it would be a better option to inflate the ETT cuff with saline (with $2 \%$ lignocaine) rather than with air alone. 
The number of coughing/ bucking episodes following reversal was compared and surprisingly, we found that, out of all the patients who did not have any cough, $87.5 \%$ received lignocaine in the cuff ETT. Of all the patients who had more than 4 episodes of coughs, all belonged to the group which received air in the cuff ETT. There was a statistically significant reduction in the number of coughs among those who received lignocaine in the cuff. This shows that lignocaine in the ETT cuff is effective in preventing bucking/coughing. This was similar to the study findings conducted by Waka Hirota. ${ }^{12}$

The reason we are interested in tackling the problem of bucking/coughing during emergence is that, it can result in a rise in blood pressure which in turn can increase the chances of bleeding, can increase intracranial tension, intraocular pressure and intra-abdominal pressure. Interestingly, when the systolic during reversal and extubation were compared among the two groups of patients, we found that those patients who received lignocaine in ETT had only a mean rise of $10.039 \mathrm{mmHg}$ as against $23.452 \mathrm{mmHg}$ mean rise among those who received air in ETT. This clearly shows that lignocaine in the cuff is also effective in reducing adverse hemodynamic changes associated with emergence.

Sore throat is reported by $30-70 \%$ of patients after tracheal intubation. ${ }^{14}$ Most often that might be the only symptom of a patient in the post-operative ward. The etiology of sore throat is thought to involve mucosal erosion caused by the cuff of the endotracheal tube, trauma from intubation, mucosal dehydration as well as patient coughing/bucking that leads to friction between tracheal mucosa and ETT. ${ }^{14,15}$ By preventing bucking and coughing at intubation, lignocaine is effective in reducing sore throat even after its pharmacological action has worn off. Our study proves that the incidence of sore throat was significantly reduced among those patients who received lignocaine in the ETT. Similar results were obtained by a study conducted by Herlevsen et al and Fagan et al. ${ }^{16,17}$

This study clearly proves the efficacy of using lignocaine in ETT cuff instead of air in reducing post-operative cough, sore throat as well as blood pressure and this is a simple, less costly method of achieving these benefits with minimum adverse reactions.

\section{Limitations}

The method of questioning is an important determinant of the incidence of sore throat. This may be due to the fact that patients concentrate on symptoms directly related to the operative site and do not immediately associate sore throat with anesthesia and surgery.

\section{CONCLUSION}

This study proves that $2 \%$ intra-cuff lignocaine is an effective method in reducing post-operative sore throat and emergence cough and thereby beneficial in controlling the hemodynamic changes associated with emergence.

Funding: No funding sources

Conflict of interest: None declared

Ethical approval: The study was approved by the Institutional Ethics Committee

\section{REFERENCES}

1. Harding C, McVey F. Interview method affects incidence of postoperative sore throat. Anaesthesia. 1987;42:1104-7.

2. Chung HPF, Mezei G. Post-operative sore throat after ambulatory surgery. Br J Anaesth. 2002;88:582.

3. Steinhaus JE, Gaskin I. A study of intravenous lidocaine as a suppressant of cough reflex. Anesthesiology. 1963;24:285-90.

4. Yukioka H, Yoshimoto N, Nishimura K, Fujimori M. Intravenous lidocaine as a suppressant of coughing during tracheal intubation. Anesth Analg. 1985;64:1189-92.

5. Stoelting RK. Blood pressure and heart rate changes during short duration laryngoscopy for tracheal intubation: influence of viscous or intravenous lidocaine. Anesth Analg. 1978;57:197-9.

6. Stoelting RK. Circulatory changes during direct laryngoscopy and tracheal intubation: influence of duration of laryngoscopy with or without prior lidocaine. Anesthesiology. 1977;47:381-3.

7. Hamill JF, Bedford RF, Weaver DC, Colohan AR. Lidocaine before endotracheal intubation: intravenous or laryngotracheal. Anesthesiology. 1981;55:578-81.

8. Prengel AW, Lindner KH, Hahnel JH, Georgieff M. Pharmacokinetics and technique of endotracheal and deep endobronchial lidocaine administration. Anesth Analg. 1993;77:985-9.

9. Sagheer AS, Iqbal M, Ali K. Effect of Intracuff Lignocaine on Coughing during Emergence and Postoperative Sore Throat. Pakistan J Med Health Sci. 2009;3:1.

10. Camporesi EM, Mortola JP, Ambrogio SF, Ambrogio SG. Topical anesthesia of tracheal receptors. J Appl Physiol. 1979;47:1123-6.

11. Sconzo JM, Moscicki JC, Fazio DCA. In vitro diffusion of lidocaine across endotracheal tube cuffs. Reg Anesth. 1990;15:37-40.

12. Hirota W, Kobayashi W, Igarashi K. Lidocaine added to a tracheostomy tube cuff reduces tube discomfort. Canadian J Anesthesia J Canadiend Anesthesie. 2000;47:414.

13. Combes X, Schauvliege F, Peyrouset O. Intra-cuff pressure and tracheal morbidity: Influence of filling cuff with saline during nitrous oxide anesthesia. Anesthesiology. 2001;95:1120.

14. Altintas F, Bozkurt P, Kaya G, Akkan G. Lidocaine $10 \%$ in the endotracheal tube cuff: blood 
concentrations, haemodynamic and clinical effects. European J Anaesthesiology. 2000;17:436-42.

15. Navarro LH, Braz JR, Nakamura G, Lima RM, Silva Fde P, Modolo NS. Effectiveness and safety of endotracheal tube cuffs filled with air versus filled with alkalinized lidocaine: a randomized clinical trial. Sao Paulo Med J. 2007;125(6):322-8.

16. Herlevsen P, Bredahl C, Hindsholm K, Kruhoffer P. Prophylactic laryngo-tracheal aerosolized lidocaine against postoperative sore throat. Acta Anaesthesiol Scand. 1992;36:505-7.
17. Fagan C, Friesel HP, Laffey J, Hannon V, Carey M. The effects of intra-cuff lidocaine on endo-tracheal tube induced emergence phenomena after general anesthesia. Anesth Analg. 2000;91(1):201-5.

Cite this article as: Abraham JM, Abraham S, Varghese SM. How effective is intra-cuff lignocaine in reducing post-operative sore throat and emergence cough: a comparative study. Int J Basic Clin Pharmacol 2020;9:1226-31. 